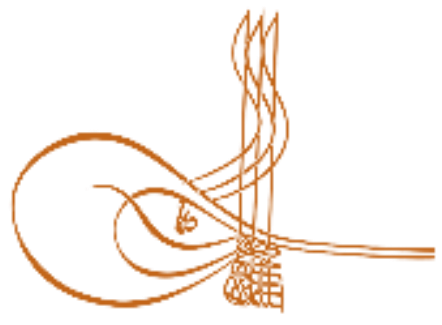

www.turkishstudies.net/social
Turkish Studies - Social Sciences

eISSN: $2667-5617$

Research Article / Araşttrma Makalesi

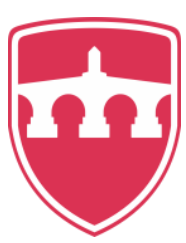

INTERNATIONAL

BALKAN

UNIVERSITY

Sponsored by IBU

\title{
Kraliçe Arı Sendromu ve Hemşirelik Mesleği*
}

Queen Bee Syndrome and Nursing

\author{
Melike Taşdelen Baş**
}

\begin{abstract}
Regarding the position of women in society, low gender identity emerges as an effort to show the leadership skills of men. With this masculine leadership feature, the woman will have to glorify her business life and harm other women in her work environment. This situation is referred to the literature as "queen bee syndrome". This term also includes environments where women work more. The fact that female bosses or managers cause stress on women workers has been faced recently. Depression and stress are more common in women managed by women. The main symptoms of the syndrome are that women managers see other women employees as threats due to the need to glorify success and jealousy. Especially in the field of health and nursing, we encounter this situation. The occurrence of queen bee syndrome in the nursing profession, which is a woman-based profession, depends on various reasons. These include fear of an experienced nurse being replaced by an inexperienced nurse. At the same time, it is reflecting this unhappiness to young nurses who have not yet encountered these difficulties by seeing negative aspects such as the desire of being experienced or managing nurse to be better, long working hours, unfair wages, and high workload. For this reason, entrepreneurship and in-service studies should be conducted in healthcare institutions that take into account demographic characteristics such as age and gender. These activities should be integrated into working life. Supporting other female employees in female management positions will increase motivation more. In the future, in order to change the perspectives of the nurses on the profession positively and to increase motivation in the profession, there is a need for studies examining the views on the queen bee syndrome experienced in the nursing profession, investigating the causes, and suggestions for solution.
\end{abstract}

Structured Abstract: : There is an effort to suppress women's gender roles, to underestimate their gender identity, and to demonstrate the same leadership skills as men. With this ability in the hands of women, she will be in the position of glorifying herself in her business and harming other women in her workplace. This situation is referred to the literature as "queen bee syndrome". It is very common for women to encounter an obstacle, especially in their business life. This obstacle is indicated as an invisible ceiling. Behavioral scientists named this invisible obstacle "Glass Ceiling". The glass ceiling is defined as the obstacles placed by women in the executive position at the top in line with their own wishes. It is tried to be explained that the

\footnotetext{
* Bu çalışma, 5. Uluslararası Sosyal Bilimler Kongresi’nde (2019) sözlü bildiri olarak sunulmuştur.

** Öğr. Gör. Dr., Selçuk Üniversitesi, Akşehir Kadir Yallagöz Sağlık Yüksekokulu, Hemşirelik Bölümü

Lect., Selçuk University Akşehir Kadir Yallagöz Health Academy, Department of Nursing ORCID 0000-0002-2389-7696

melikebas@selcuk.edu.tr
}

Cite as/ Atıf: Taşdelen Baş, M. (2020). Kraliçe arı sendromu ve hemşirelik mesleği, Turkish Studies - Social, 15(1), 807-815. https://dx.doi.org/10.29228/TurkishStudies.39398

Received/Geliş: 21 October/Ekim 2019

Accepted/Kabul: 25 February/Şubat 2020

Copyright $(\mathcal{C}$ INTAC LTD, Turkey 
women who have reached a high position or climbed in their business life have encountered an obstacle and hit a ceiling at the point they reached. The fact that female bosses or managers cause stress on women workers has been faced recently. Depression and stress are more common in women managed by women. The main symptoms of the syndrome are that women managers see other women employees as threats due to the need to glorify success and jealousy. Queen bee syndrome is one of the factors that cause glass ceiling syndrome. The queen bee in the beehives struggles to be in a managerial position and to remain in power. Similarly, in business life, it is foreseen that executive women, who have the characteristics of queen bees, think in the same way and struggle to stay in power. In bee colonies, all worker bees pay special attention to a bee that is larger than them. The queen bee, whose safety, cleaning and nutritional needs are met by other bees, ensures the continuity of the colony. Queen bee is of great importance for other bees. Aware of this situation, the queen bee tries to maintain its position. If you are a woman employee who works under a female manager and your manager shows an opposing attitude to you, and also makes your life difficult; your manager can be said to have queen bee syndrome. Since the female manager with queen bee syndrome perceives other women around her as a threat, she tries to prevent their development and change her strength and position. The cause of jealousy is very evident, as is the need for women to be satisfied and better than others. Another reason for older nurses to attack aggressively against young nurses is an anger in their living conditions. Just like other healthcare jobs, nursing is a very tiring job due to long working hours, unfair wages, grumpy customers, and huge workloads that cause large-scale workloads. This anger is often directed to new and young nurses who have not yet experienced these experiences. In a study by Wuertele (2017), she interviewed a young nurse named Sienna about the queen bee syndrome. An interview; it is stated that older nurses do not want successful young nurses. It is reported that elderly nurses do not help new graduates and treat them rudely. In the study of Şengül et al. (2019), the perception of queen bee in nurses was evaluated. In the study, nurses stated that they found female managers more emotional and less successful in problem solving than male managers. In addition, it was concluded that female managers are compatible with queen bee syndrome by stating that they create an environment of competition and conflict in the workplace. Women continue to be at the forefront of an increasingly demanding and constantly changing system in higher education. A unique role that seems to be the plague that develops in the Academy is "Queen Bee Syndrome". While some educators and forensic experts consider this behavior as a form of bullying or persecution of a woman forced by women against other women, other settings characterize it as systemic discrimination and narcissistic attitudes and behaviors at the expense of other competent female colleagues or subordinates. Newcomers to the academy often believe that other women will provide attention and assistance for emotional and professional support in the field of mutual understanding and similar identity in the workplace. Many individuals feel more at the center of the attacks of queen bees in the environment in which they work. Queen bees can prevent talented women from accessing the working environment by systematically sabotaging their achievements and ongoing work or by pressing them to exit an existing position.

Keywords: Queen Bee Syndrome, Nursing, Women Employment

Öz: Kadının toplumdaki konumuna ilişkin, cinsiyet kimliğinin küçük görülmesi, erkeklerin sergiledikleri liderlik yeteneklerini gösterme çabasını ortaya çıkmaktadır. Kadın ortaya çıkardığı bu erkeksi liderlik özelliği ile, iş yaşamında yüceltme ve çalıştığ 1 iş ortamında diğer kadınlara zarar verme durumunda olacaktır. Bu durum literatüre, "kraliçe arı sendromu" olarak geçmiştir. Bu terim aynı zamanda kadınların daha çok çalıştığı ortamları da içermektedir. Kadın patron ya da yöneticilerin, kadın çalışanlar üzerinde strese neden olduğu gerçeği ile son zamanlarda çok fazla karşılaşılmaktadır. Kadınlar tarafından yönetilen kadınlarda depresyon ve strese daha çok rastlanmaktadır. Kadın yöneticilerin başarıyı yüceltme ihtiyacı, kıskançlık gibi nedenler ile, diğer kadın çalışanları tehdit unsuru olarak görmesi sendromun başlıca belirtileridir. Özellikle sağlık ve hemşirelik alanında da bu durum ile karşılaşmaktayız. Kraliçe arı sendromunun, kadın ağırlıklı bir meslek olan hemşirelik mesleğinde görülmesi çeşitli nedenlere bağlıdır. Bu nedenler arasında deneyimli bir hemşirenin kendi yerini daha tecrübesiz bir hemşire tarafından alması korkusu sayılabilir. Aynı zamanda deneyimli ya da yönetici hemşirenin daha iyi olma isteği, iş yükünün fazla olması, haksız ücret, uzun süren çalışma saatleri gibi negatif yönlerini görerek bu memnuniyetsizliğini, henüz bu zorluklarla karşılaşmamış genç hemşirelere yansıtma durumudur. Bu nedenle, sağlık hizmetinin verildiği kurumlarda, girişimcilik ile ilgili bilgiler verilmeli ve hizmet içi çalışmalar yapılmalıdır. Yapılan etkinlikler çalışma yaşamına entegre edilmeye çalışılmalıdır. Yönetici pozisyonundaki kadın çalışanların diğer kadın çalışanları desteklemesi motivasyonu daha çok artıracaktır. Gelecekte, hemşirelerin mesleğe ilişkin bakış açılarının olumlu yönde

Turkish Studies - Social, 15(1) 
değiştirilmesi ve meslekte motivasyonun artması amacı ile, hemşirelik mesleğinde yaşanan kraliçe arı sendromuna ilişkin görüşlerin incelendiği, nedenlerin araştırıldığı ve çözüme ilişkin önerilerin yer aldığı çalışmalara gereksinim vardır.

Anahtar Kelimeler: Kraliçe Arı Sendromu, Hemşirelik, Kadın İstihdamı

\section{Giriş}

Dünya nüfusunun yarısını kadınların oluşturmasına karşın, iş hayatında bu oranda kendilerini temsil edememektedirler. Ayrıca üst düzey yöneticilik pozisyonunda, erkeklere oranla daha düşük bir paya sahiptirler (Alcorn, 1995). Günümüzün şartlarında, kadınların işgücüne ve eğitime katılımlarında oldukça hızlı bir artış görülmektedir. Ancak yöneticilik ya da üst düzey pozisyonlarda kadınların bir engelle karşılaştığı bildirilmektedir. Kadınların düşük ücret ve düşük statülü işlerde çalışmaları toplum tarafından kabul edilebilirken, yöneticilik pozisyonunun kadına göre olmadığı düşünülmektedir. Dolayısıyla kadınların meslekte yükselmeleri daha güç olmaktadır. (İnandı vd., 2009). İş hayatında başarılı olan kadınların yaşadıkları dinlenildiğinde, kadın olmaya bağlı yaşanan haksızlıklar ve karşılarına gelen sıkıntılarla dolu olduğu görülmektedir. Kariyerlerine ulaşırken düz bir çizgiyi değil bir labirenti takip ettikleri anlaşıllabilir (Ellemers, 2014). Kadının toplumdaki konumuna ilişkin, cinsiyet kimliğinin küçük görülmesi, erkeklerin sergiledikleri liderlik yeteneklerini gösterme çabasını ortaya çıkmaktadır. Kadın ortaya çıkardığı bu erkeksi liderlik özelliği ile, iş yaşamında yüceltme ve çalıştığı iş ortamında diğer kadınlara zarar verme durumunda olacaktır. Bu durum literatüre, "kraliçe arı sendromu" olarak geçmiştir. İlk olarak tanımı 1970'li yıllarda yapılan "Kraliçe arı" terimi, ataerkil olan toplumlarda başarılı ve yalnız olan kadınların, aynı iş ortamında bulundukları kadınların gelişimine yardımcı olmayarak, onları engelleyici şekilde davranmaları olarak tanımlanmaktadır. Kraliçe arı kavramı daha çok kadınların hakim olduğu ortamları içermektedir. Özellikle sağlık ve hemşirelik alanında da karşımıza çıkmaktadır. Bu derlemede kraliçe arı sendromu ve hemşirelik alanındaki boyutları incelenmiştir.

\section{İş Yaşamı ve Kadınlar}

Erkeklerin egemen olduğu bir iş ortamında, yöneticilik pozisyonunu elde etmek güç olmaktadır. Lider özellikleri genellikle erkeksi ya da eril özellikler gösteren bir profildir ve kadınların cinsiyet özellikleri bu rol ile uyuşmamaktadır (Derks vd., 2016). Faniko ve arkadaşlarının (2016) çalışmasında, İsviçre'de çalışmakta olan 315 kadın işçi ile görüşülmüştür. Çalışmaya katılan kadınlara, erillik seviyeleri ve kendilerinden daha düşük pozisyonda çalışan kadınlara tutum ve davranışları sorulmuştur. Çalışmanın sonucunda, yönetici pozisyonunda bulunan kadınların, ailelerine öncelik vermeyen, iş hayatındaki kendine benzeyen başarılı kadınlarla daha fazla özdeşleştirdikleri ortaya çıkmıştır. Ayrıca, kendilerini yönetici pozisyonundaki kadınların ailesini önemseyen ve iş hayatından daha başarısız kadınlara benzetmedikleri ve onlara daha az destek oldukları belirtilmiştir. Bunun yanında çalışmaya katılan yönetici kadınlar, kendilerini kariyer odaklı ve daha erkeksi olarak tanımlamışlardır. (Faniko vd., 2016). Güç ve iktidar sahibi olan kadınların, hedeflerine ulaşmak için, kadın astlarına engel olmayı tercih ettikleri görülmektedir (Derks vd., 2011).

\section{Cam Tavan ve Kraliçe Arı Sendromu}

Kadınların özellikle iş yaşamlarında yükselirken, bir engelle karşılaşmalarına çok rastlanmaktadır. $\mathrm{Bu}$ engel, görünmez bir tavan olarak belirtilmektedir. Davranış bilimciler bu görünmez engele "Cam Tavan" adını vermişlerdir. Cam tavan, en tepede bulunan yönetici pozisyonundaki kadınların, kendi istekleri doğrultusunda koydukları engeller olarak tanımlanmaktadır. İş yaşamlarında yüksek pozisyona gelen ya da tırmanan kadınların, ulaştıkları noktada bir engelle karşılaştıkları ve bir tavana vurdukları anlatılmaya çalışılmaktadır (Aytaç, 2001).

www.turkishstudies.net/social 
Cam tavan kavramı ilk kez, kadınların iş yaşamlarında bir üst pozisyona geçtiği sırada karşılaştığı engeller ve haksızlıklar olarak kullanılmıştır (Lockwood, 2004). Çoğu zaman toplumsal cinsiyet ayrımcılığının bir sonucu olarak bazı uygulamaların arkasına gizlenmektedir. (Çetin, 2011). Cam tavan algısına neden olan faktörler arasında yer alan "Kadın Tarafindan Konulan Engeller" kapsamında, "Kendini Referans Alma Yanılgısı" ve "Kraliçe Arı Sendromu" yer almaktadır (Öztürk ve Cevher, 2015). Kendini referans alma yanılgısı; Kadın yöneticilerin "Ben bu pozisyona nasıl geldiysem, herkes bu pozisyona gelebilir. Özel bir çaba gösterilmesine gerek yok düşüncesidir." "Kraliçe arı" sendromu; Üst yönetimde görülen 'tek kadın' olmanın bir başarı ve ayrıcalık göstergesi olduğuna inanmaktır (Örücü vd., 2007).

Kadın patron ya da yöneticilerin, kadın çalışanlar üzerinde strese neden olduğu gerçeği ile son zamanlarda çok fazla karşılaşılmaktadır. Kadınlar tarafından yönetilen kadınlarda depresyon ve strese daha çok rastlanmaktadır. Kadın yöneticilerin başarıyı yüceltme ihtiyacı, kıskançlık gibi nedenler ile, diğer kadın çalışanları tehdit unsuru olarak görmesi sendromun başlıca belirtileridir (Mengi, 2010).

Kraliçe arı sendorumu, cam tavan sendromuna neden olan faktörlerden biridir. Ar1 kovanlarındaki kraliçe arı, yönetici pozisyonunda olma ve iktidarda kalma mücadelesi vermektedir. Buna benzer olarak iş hayatında da kraliçe arı özelliklerini taşıyan yönetici kadınların aynı şekilde düşündüğü ve onun da iktidarda kalma mücadelesi verdiği öngörülmektedir. Arı kolonilerinde tüm işçi arılar, kendilerinden büyükçe olan bir arıya ayrı özen göstermektedirler. Güvenlik, temizlik ve besin ihtiyacı diğer arılar tarafından karşılanan kraliçe arı, koloninin devamlılığını sağlamaktadır. Kraliçe arı diğer arılar için büyük önem taşımaktadır. Bu durumun farkında olan kraliçe arı, konumunu sürdürmek için çabalamaktadır (Yürüten, 2010)

Eğer bir kadın yönetici altında çalışan bir kadın çalışan iseniz ve yöneticiniz size karşııt bir tutum sergiliyor ise, aynı zamanda hayatınızı zorlaştırıyorsa; yöneticinizin kraliçe arı sendromu olduğu söylenebilir. Kraliçe arı sendromu olan kadın yönetici, çevresinde bulunan diğer kadınları tehdit olarak algıladığından, bu kadınların gelişimini engellemek, gücünü ve pozisyonunu değiştirmek için çabalamaktadır (Bickford, 2011).

Daha çok erkeklerin varsayıldığı iş dünyasında mobbing mağduru kadınlar, psikolojik engelleri aştıkları zaman, kendilerinden geride kalan kadınlara erkeklerin uyguladığı davranışları göstermektedirler. Kraliçe arı sendromunun denilen bu durumda, erkek tutumları benimsenerek, kadınlarla rekabeti ortadan kaldırmak amaç edinilmiştir (Zel, 2002). Derks ve arkadaşlarının çalışmasında, çalışan kadınların, diğer kadınları dışlayarak, onları küçük görmelerinin nedeninin, cinsiyet odaklı ve daha önceki olumsuz deneyimlerden kaynaklandığı bildirilmektedir (Derks vd, 2011). Faniko ve arkadaşlarının çalışmasında (2016), kraliçe arı sendromuna sahip kadınların herkese aynı tavrı göstermedikleri belirlenmiştir (Faniko vd., 2016).

\section{Hemşirelik Mesleği}

Hemşirelik en çok kadınlardan oluşan bir meslek grubudur. Aynı statüde olduğu meslektaşları arasında şiddete uğrayan hemşirelerde, fiziksel, psikolojik sağlık sorunları ortaya çıkabilmektedir. Bunun yanında sosyal ilişkilerde çatışmalar, intihar düşüncesi, sosyal izolasyon gibi problemler ortaya çıkabilmektedir (Bloom, 2019; Mckenna vd., 2003).

Mobbing (psikolojik yıldırma), çalışma hayatında ortaya çıkan, gerilimli bir ortam oluşturan bir durumdur. Çalışanların ve işverenin huzurunu bozan, rahatsız edici, ahlak dışı bir durum olup, bir tür psikolojik şiddettir (Tetik, 2010; Mercanlığlu, 2010).

Hemşirelik alanında psikolojik şiddet ve mobbing içeren çalışmalar incelendiğinde, hasta bakımının etkilendiği ve hemşirelerin mesleklerini bırakmak istedikleri ortaya çıkmaktadır.

Mckenna ve arkadaşlarının çalışmasında (2003), çalışma arkadaşlarının şiddetine maruz kalan hemşirelerin, hastalarına verdikleri bakımda olumsuz etkilenme yaşadıkları belirtilmiştir. 
Ayrıca hemşirelerin, hasta başında daha uzun süre geçirdikleri, daha sık bölüm değiştirme yaptıkları belirtilmiştir (Mckenna vd, 2003). Roche ve arkadaşlarının çalışmasında, meslektaşlarının şiddetine maruz kalan hemşirelerin, ilaç hazırlığı sırasında hata yaptıkları, hastaların sağlığına ilişkin uygulamalarda hata yaptıkları belirtilmektedir (Roche vd, 2010).

Griffin tarafindan, şiddete maruz kalan hemşirelerin üzgün ve daha az enerjiye sahip oldukları belirtilmektedir. Aynı zamanda verdikleri hasta bakım kalitesinde azalma ve meslektaşlarına soru sormaya çekinmektedirler (Griffin, 2004). Griffin'in başka bir çalışmasında, işe yeni başlayan hemşirelerin \%60'ının meslektaşlarının şiddetine maruz kaldığı bildirilmektedir. $\mathrm{Bu}$ hemşirelerin \%20'si mesleklerini bırakmak istediklerini iletmişlerdir (Griffin, 2005). Başka bir çalışmada, hemşirelerin \%21'nin şiddete maruz kaldığı bildirilmektedir (Purpora vd., 2012). İtalya'da yapılan bir çalışmada, hemşireler ve öğrenci hemşirelerin maruz kaldığı şiddet araştırılmıştır. Hemşirelik öğrencilerinin \%34'ü, çalışan hemşirelerin ise, \%43'ünün şiddete maruz kaldığı bildirilmiştir. Çalışmada sözel şiddet, düşük sosyal destek ve düşük kurumsal adalet ile ilişkilendirilmiştir (Magnavite ve Heponiemi, 2011).

Ülkemizde ise Yıldırım ve arkadaşlarının lisans düzeyinde eğitim veren hemşirelik okullarında yaptıkları bir araştırmada, akademisyen hemşirelerin \%82'sinin kişiliğe yönelik mobbinge uğradıkları saptanmıştır (Yıldırım vd., 2007). Yıldırım ve Yıldırım'ın hemşireler üzerinde yaptıkları bir araştırmada, katılımcıların \%86'sı çoğunlukla yöneticileri tarafından olmak üzere, son bir y1l içerisinde mobbing davranışları ile bir ya da daha fazla kez karşılaştıklarını bildirmişlerdir (Yıldırım ve Yıldırım, 2007). Bahçeci Geçici ve Sağkal'ın çalışmasında hemşirelerin \%32.8'inin yöneticisi tarafından mobbinge maruz kaldığı saptanmıştır (Geçici vd., 2011).

Demir ve arkadaşlarının çalışmasında, hemşirelerin \%11,9'u mobbinge maruz kaldıklarını, \%12,7'si yönetici tarafından , \%7,1'i ise aynı serviste çalıştığ hemşire meslektaşı tarafından mobbinge uğradığını ifade etmiştir. \%14,5'u mobbing sonrası hiçbir tepki vermediğini ifade etmiş̧tir (Demir vd., 2014). Turan'ın (2006) İstanbul'da 55'i hemşire olan 152 sağlik personeli ile yaptığı araştırmanın sonucuna göre mobbing uygulayanların en çok kadınlar olduğu belirtilmektedir (Turan, 2006).

Özen Çöl (2009) tarafindan Muğla'da 28'i hemşire olan 272 sağlık çalışanı ile yapılan bir araştırmada eğitim düzeyi yüksek ve genç olan hemşirelerin mobbinge daha çok uğradıkları ortaya çıkmıştır (Özen Çöl, 2009). Simons ve Mawn'ın 2010 yılında 184 hemşire ile tanımlayıcı olarak yaptığı bir araştırmada işe yeni başlayan genç hemşirelerin daha çok mobbing davranışına maruz kaldığı belirlenmiştir (Simons ve Mawn, 2010).

Kıskançlık nedeni, kadınlar arasında memnun olma ve diğerlerinden daha iyi olma ihtiyacı olduğu gibi çok belirgindir. Yaşl1 hemşirelerin genç hemşirelere karşı saldırgan bir şekilde saldırmaları için bir başka neden, kendi yaşam koşullarında bir öfkedir. Tıpkı sağlıkla ilgili diğer meslekler gibi, hemşirelik, uzun çalışma saatlerine, haksız ücrete, huysuz müşterilere ve büyük çaplı iş yüküne neden olan devasa iş yüklerine bağlı çok yorucu bir iştir. Bu öfke genellikle, bu deneyimleri henüz yaşamamış yeni ve genç hemşirelere yönlendirilmektedir (www.mightynurse.com, 2019).

Wuertele'nin (2017) yapmış olduğu çalışmada, Sienna adında genç bir hemşire ile kraliçe arı sendromu hakkında bir röportaj yapmıştır. Röportajda; daha yaşlı olan hemşirelerin başarılı olan genç hemşireleri istemedikleri belirtilmektedir. Yaşlı hemşirelerin yeni mezunlara yardım etmediklerini, onlara kaba davrandıklarını bildirilmektedir (Wuertele, 2017).

Şengül ve arkadaşlarının (2019) yaptığı çalışmada, hemşirelerde kraliçe arı algısı değerlendirilmiştir. Çalışmada hemşireler, kadın yöneticileri erkek yöneticilere göre daha duygusal ve problem çözme konusunda daha az başarılı bulduklarını belirtmişlerdir. Ayrıca, kadın 
yöneticilerin işyerinde rekabet ve çatışma ortamı oluşturduklarını belirtilerek, kraliçe arı sendromuna uyumlu oldukları sonucuna varılmıştır (Şengül vd., 2019).

Kadınlar yükseköğretimde artan talepkar ve sürekli değişen bir sistemin ön saflarında yer almaya devam etmektedir. Akademi'de gelişen veba gibi görülen benzersiz bir rol "Kraliçe Arı Sendromu" dur. Bazı eğitimciler ve adli tıp uzmanları, bu davranışı, diğer kadınlara karşı kadınların zorla çalıştırdığı bir kadının zorbalık veya kadın zulmü biçimi olarak görürken, diğer ortamlar, davranışı diğer yetkili kadın meslektaşlarının veya astlarının pahasına sistemik ayrımcılık ve narsisistik tutum ve davranışlar olarak nitelendirmektedir. Akademiye yeni gelenler, genellikle diğer kadınların işyerinde karşılıklı anlayış ve benzeri kimlik konularında duygusal ve profesyonel destek için dikkat ve yardım sağlayacağına inanmaktadır. Birçok birey çalıştığ kendilerini kraliçe arıların saldırılarının merkezinde daha çok hissetmektedir. Kraliçe arılar, yetenekli kadınların başarılarını ve devam eden işlerini sistematik olarak sabote ederek ya da mevcut bir pozisyondan çıkmaları için baskı yaparak çalışma ortamına erişmelerini önleyebilmektedirler (Mckoy, 2013).

\section{Sonuç ve Öneriler}

-Hemşirelerin mobbinge yönelik olarak hem bireysel hem de kurumsal olarak güçlendirmeleri gerekmektedir. Buna yönelik olarak iş ortamında mobbinge uğrayan bir çalışanın başvurabileceği rehberler ve yönergeler olmalıdır. Çalışanların yaşadıkları durumları rapor edebilmesine yönelik alt yapı oluşturulmalıdır. Mobbinge maruz kalan çalışanlar, yaşadıklarını ifade etmede cesaretlendirilmelidir.

-Çalışanlara, mobbing konusunda bilinçlendirme eğitiminin yapılmalıdır.

-İşe yeni başlayan sağlık çalışanlarına yapılan yıldırma; tanımlama, baş etme, kişiler arası ilişkiler, stres ve stresle baş etme, kendini ifade etme gibi eğitimler verilmesi ve iş yerine uyum için oryantasyon programı düzenlenmelidir.

-Ebelik ve hemşirelik müfredat programlarında mobbing tanımı, etkileri, baş etme ve hukuki çerçevesi konusu eklenmelidir.

-Kadın yöneticilerin, kendi güçlü ve zayıf yönlerini bilmesi gerekmektedir. Grup çalışmalarında, ortaya çıkabilecek olumsuz sonuçları kabul edebilmeli ve olumsuzlukları deneyim olarak değerlendirebilmelidir. Bunun için yöneticilere, yönetim, liderlik ve özgüven konularını içeren eğitimler verilmelidir. Yönetim kabiliyetlerinin artırılması için, eğitim faaliyetleri içinde uygulama yaptırılmalıdır. Eğitim faaliyetleri ile kadın yöneticilere, esnek, değişime açık ve dürüst olma, adalet ve tutarlılık özelliklerine sahip ve etik kurallara bağlı olma gibi özellikler kazandırılarak, başarılı liderlik özelliklerine sahip olmaları sağlanacaktır. Akademik ortamda yaşanan ve kadın cinsiyetinin daha fazla olduğu hemşirelik okullarında, kadının kadına yapmış olduğu mobbing hususunda, adli düzenlemeler ile sorunun azaltılabileceği düşünülmektedir.

Literatürde, kraliçe arı sendromunun işlendiği ve hemşirelerin yer aldığı çalışmalar oldukça azdır. Gelecekte, hemşirelerin mesleğe ilişkin bakış açılarının olumlu yönde değiştirilmesi ve meslekte motivasyonun artması amacı ile, hemşirelik mesleğinde yaşanan kraliçe arı sendromuna ilişkin görüşlerin incelendiği, nedenlerin araştırıldığı ve çözüme ilişkin önerilerin yer aldığı çalışmalara gereksinim vardır. 


\section{Kaynakça}

Alcorn, B. (1997). Commitments Cinderella and the Glass Ceiling. Los Angeles Times. Los Angeles, California, 3.

Aytaç, S. (2001). Çift kariyerli eşler ve çalı̧̧ma yaşamındaki yeri. Ezgi Kitabevi.

Bickford, N. (2011). 'Queen bees - an evolving species or an office myth?'. financialtimes.com.

Bloom, EM. (2019). Horizontal violence among nurses. Experiences Responses and Job Performance. Nurs Forum, 54(1):77-83. doi: 10.1111/nuf.12300. Epub 2018 Oct 17.

Çetin, A. (2011). Kadın Yöneticilerin Cam Tavan Algısının Cam Tavanı Aşma Stratejilerine Etkisi: Bursa İli Tekstil Sektöründe Bir Alan Araştırması. Dumlupınar Üniversitesi Sosyal Bilimler Dergisi, 49(33), 19-34.

Demir, G., Bulucu, G., Özcan, A., Yılmaz, D., Havva, Ş. (2014). Hemşirelerin mobbinge uğrama durumlarının belirlenmesi. Düzce Üniversitesi Sağllk Bilimleri Enstitüsü Dergisi, 1(1). https://doi.org/10.33631/duzcesbed.555924.

Derks, B., Ellemers, N., Van Laar, C., De Groot, K. (2011). Do sexist organizational cultures create the Queen Bee?. British Journal of Social Psychology, 50(3), 519-535. https://doi.org/10.1348/014466610×525280.

Derks,B., Van Laar, C., Ellemers, N. (2016). The queen bee phenomenon: Why women leaders distance themselves from junior women. The Leadership Quarterly, 27(3), 456-469. https://doi.org/10.1016/i.leaqua.2015.12.007

Ellemers, N. (2014). Women at work: How organizational features impact career development. Policy insights from the behavioral and brain sciences, 1(1), 46-54. https://doi.org/10.1177/2372732214549327.

Faniko, K., Ellemers, N., Derks, B. (2016). Queen Bees and Alpha Males: Are successful women more competitive than successful men?. European Journal of Social Psychology, 46(7), 903-913. https://doi.org/10.1002/ejsp.2198.

Geçici, N.B., Sağkal, T. (2011). Ödemiş’te Çalıșan Hemşirelerin Mobbinge Maruz Kalma Durumlarının İncelenmesi. Maltepe Üniversitesi Hemşirelik Bilim ve Sanatı Dergisi, 4(1), 53-62.

Griffin, M. (2004). Teaching cognitive rehearsal as a shield for lateral violence: An intervention for newly licensed nurses. The journal of continuing education in nursing, 35(6), 257-263. https://doi.org/10.3928/0022-0124-20041101-07.

Griffin, M. (2005). Awareness of nurse-on nurse abuse helps resolve problem. Association of Perioperative Registered Nurses Management Connections, 1(5), 3.

Inandi, Y. (2009). The barriers to career advancement of female teachers in Turkey and their levels of burnout. Social Behavior and Personality: an international journal, 37(8), 1143-1152. https://doi.org/10.2224/sbp.2009.37.8.1143.

Leiper J. (2005). Nurse against nurse: how to stop horizontal violence. Nursing. 35:44-5. https://doi.org/10.1097/00152193-200503000-00037.

Lockwood, N. (2004) The Glass Ceiling: Domestic and International Perspectives. Human Resource Magazine Research Quarterly, 1-49. 
Magnavita, N., Heponiemi, T. (2011). Workplace violence against nursing students and nurses: an Italian experience. $J$ Nurs Scholarsh. 43:203-10. https://doi.org/10.1111//.15475069.2011.01392.x.

McKenna, B.G., Smith, N.A., Poole, S.J., Coverdale, J.H. (2003). Horizontal violence: experiences of Registered Nurses in their first year of practice. J Adv Nurs .42(1):90-6.

Mengi, Z. (2010). Sizin Sendromunuz Hangisi?, http://www.zeynepmengi.com/2010/08/sizinsendromunuz-hangisi?

Mercanlıoğlu, Ç. (2010). Çalışma hayatında psikolojik tacizin (mobbing) nedenleri, sonuçları ve Türkiye'deki hukuksal gelişimi. Organizasyon ve Yönetim Bilimleri Dergisi, 2(2), 37-46.

Mckoy, YD. (2013). The queen bee syndrome: A violent super bee. In International Conference on Nursing \& Emergency Medicine. 2(3).

Öztürk, U.C., Cevher, E. (2015). Isyerınde Tacızın Pembe Halı: Kadınların Kadınlara Uyguladıgı Mobbing/The Pink Version Of Harrestment in The Workplace: Mobbing to Women by Women. Uludag Universitesi Iktisadi ve Idari Bilimler Fakultesi Dergisi, 34(1), 151-174.

Örücü, E., Kılıç, R., Kılıç, T. (2007). Cam tavan sendromu ve kadınların üst düzey yönetici pozisyonuna yükselmelerindeki engeller: Balıkesir ili örneği. Yönetim ve Ekonomi, 14(2), $117-135$.

Özen Çöl, S. (2009). İşyerinde psikolojik şiddet: hastane çalışanları üzerine bir araştırma. Çalışma ve Toplum. 4, 107-134.

Purpora,C., Blegen, M.A., Stotts, N.A. (2012). Horizontal violence among hospital staff nurses related to oppressed self or oppressed group. $J$ Prof Nurs. 28:306-14. https://doi.org/10.1016/j.profnurs.2012.01.001.

Roche, M., Diers, D., Duffield, C., Catling-Paull, C. (2010). Violence toward nurses, the work environment, and patient outcomes. $J$ Nurs Scholarsh. 42:13-22. https://doi.org/10.1111/j.1547-5069.2009.01321.x.

Simons, S.R., Mawn, B. (2010). Bullying in the workplace-A qualitative study of newly licensed registered nurses. AAOHN journal, 58(7), 305-311. https://doi.org/10.3928/0891016220100616-02.

Şengül, H., Cinar, F., Bulut, A. (2019). The perception of queen bee phenomenon in nurses; qualitative study in health sector. Nigerian journal of clinical practice, 22(7), 906. https://doi.org/10.4103/njcp.njcp 30818.

Tetik S. (2010). Mobbing kavramı: Birey ve örgütler açısından önemi. Karamanoğlu Mehmetbey Üniversitesi Sosyal ve Ekonomik Araştırmalar Dergisi, 2010(1), 81-89. https://doi.org/10.18493/kmusekad.24572.

Turan, F. (2006). İsyerlerinde Psikolojik Yıldırma Olgusu ve Konuya İlişkin Bir Araştırma, İstanbul üniversitesi Sosyal Bilimler Enstitüsü İşletme Ana Bilim Dalı İnsan Kaynakları Yönetimi Bilim Dalı, Yayınlanmamış Yüksek Lisans Tezi, İstanbul, Türkiye.

Yildirim, D., Yildirim, A., Timucin, A. (2007). Mobbing behaviors encountered by nurse teaching staff. Nursing Ethics. 14(4), 447-463. https://doi.org/10.1177/0969733007077879.

Yıldırım, A., Yıldırım, D. (2007). Mobbing in the workplace by peers and managers: mobbing experienced by nurses working in health care facilities in Turkey and its effect on nurses. Journal of Clinical Nursing. 16:1444-1453. https://doi.org/10.1111/j.13652702.2006.01814.x. 
Wuertele, R. (2017). The Influence Of The Queen Bee Syndrome On The Attitudes, Behaviors, And Emerging Leadership Styles Of The Millennials.

Yürüten, M.T. (2010). İş Yaşamındaki Kadınlar/Kraliçe Arı Sendromu. http://www.miradanismanlik.com/makale.php?id=26

Zel, U. (2002). İş arenasında kadın yöneticilerin algılanması ve kraliçe arı sendromu. Amme İdaresi Dergisi, 35(2), 39-48

(www.mightynurse.com) Erişim tarihi: 20.01.2019. 